\title{
Distinct Modes of Tissue Expansion in Free versus Earlier-Confined Boundaries for More Physiological Modeling of Wound Healing, Cancer Metastasis, and Tissue Formation
}

\author{
Abhimanyu Kiran ${ }^{\mathrm{a} *}$, Navin Kumar ${ }^{\mathrm{a}}$, and Vishwajeet Mehandia ${ }^{\mathrm{b}, *}$ \\ ${ }^{a}$ Department of Mechanical Engineering, Indian Institute of Technology Ropar, Rupnagar-140001, \\ Punjab, India \\ ${ }^{\mathrm{b}}$ Department of Chemical Engineering, Indian Institute of Technology Ropar, Rupnagar-140001, \\ Punjab, India \\ *Corresponding author(s) Email: abhimanyu.kiran@iitrpr.ac.in, vishwajeet@iitrpr.ac.in
}

Index

\begin{tabular}{|l|l|l|}
\hline Contents & \multicolumn{1}{|c|}{ Page \# } \\
\hline Figure S1. & The expansion and migration rates of the GDM and MDM. & S1 \\
\hline Figure S2. & $\begin{array}{l}\text { The schematic representation of the procedure used for z-stack image } \\
\text { analysis. }\end{array}$ & S2 \\
\hline Figure S3. & Leader cell pulls to stretch the cells of the $2^{\text {nd }}$ row. & S2 \\
\hline Figure S4. & Expansion of static cell clusters. & S3 \\
\hline
\end{tabular}
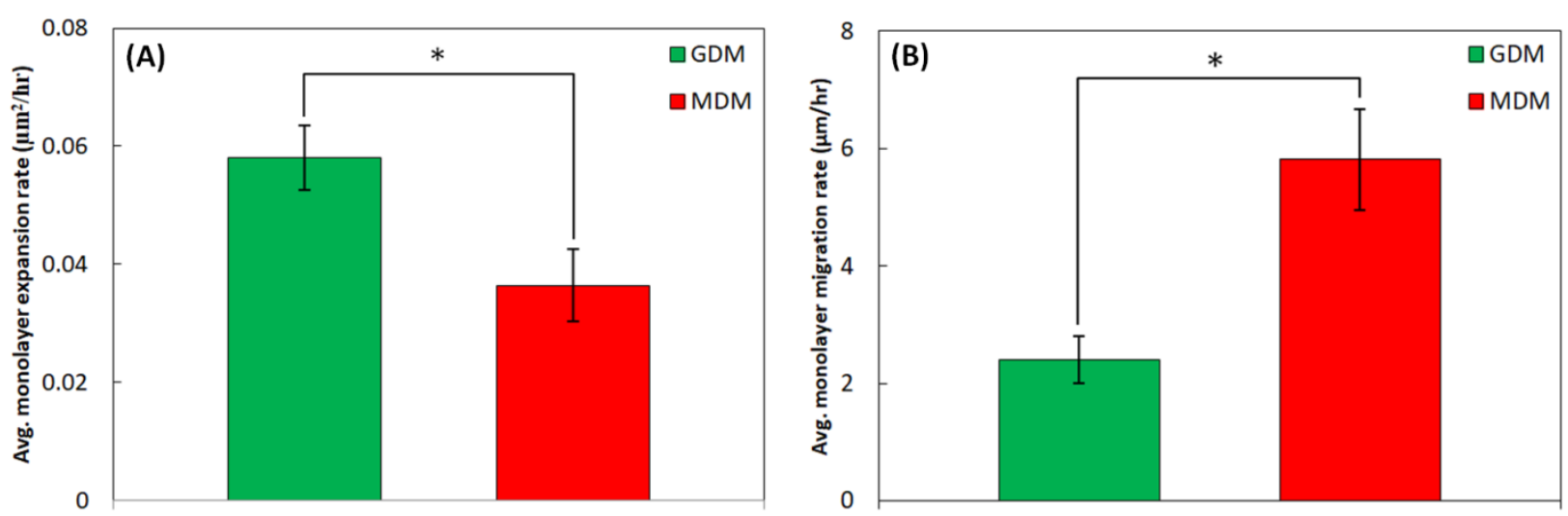

Figure S1. The expansion and migration rates of the GDM and MDM. (A) Average monolayer expansion rate, (B) Average monolayer migration rate. Note: In both cases, the unpaired t-test was applied between the GDM and MDM. Note: The standard error bars are 
plotted from 5 independent experiments. The unpaired t-test is applied between the GDM and MDM. The * represents the significance level of $\mathrm{p}<0.05$.

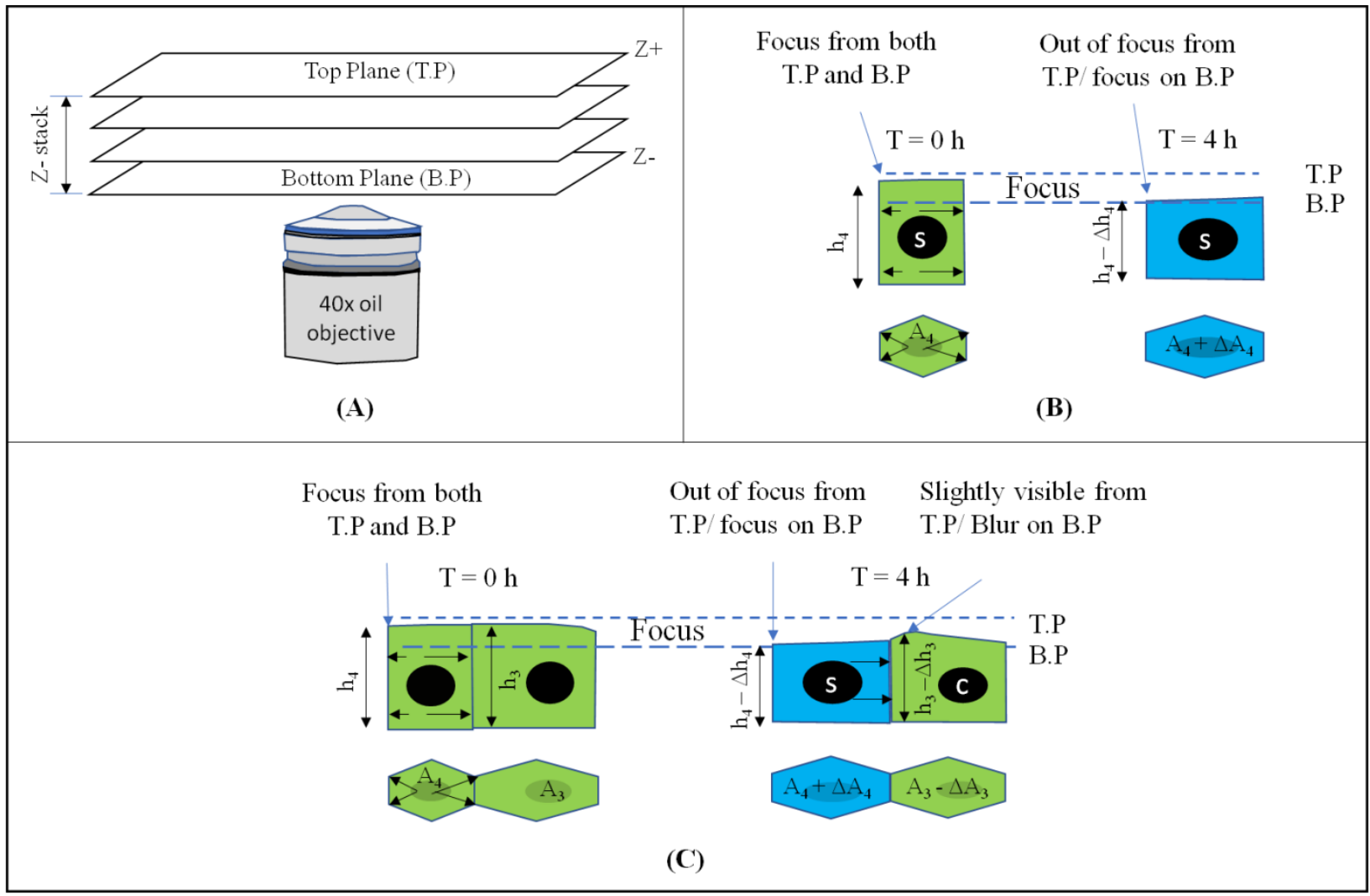

Figure S2. The schematic representation of the procedure used for z-stack image analysis. (A) Selection of z-stack for the experiment, (B) Spreading of the cell as it reduces in height and increases in the area, (C) The spreading cell push its neighboring cell, as a result of this the neighboring cell increase in height and reduce in area.
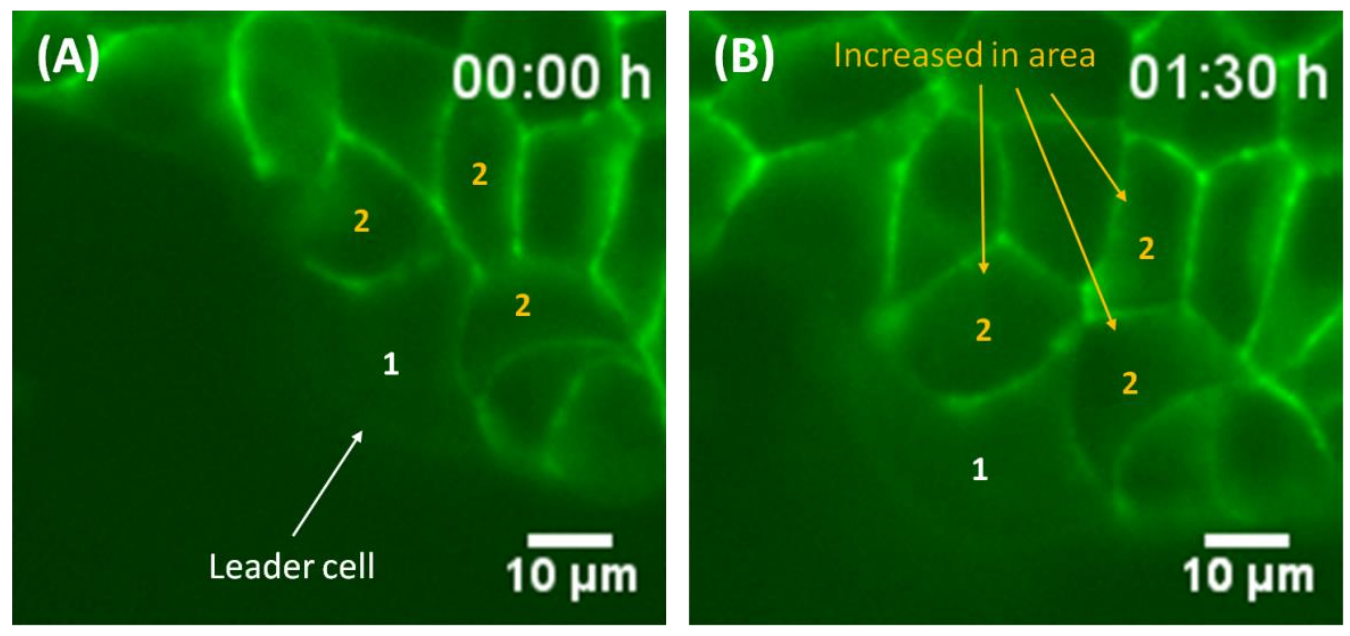
Figure S3. Leader cell pulls to stretch the cells of the $2^{\text {nd }}$ row. (A) The initial area of $2^{\text {nd }}$ row cells before stretching at $\mathrm{t}=0 \mathrm{hr}$, (B) Final area of the $2^{\text {nd }}$ row cells after stretching at $\mathrm{t}=1.5$ hr.
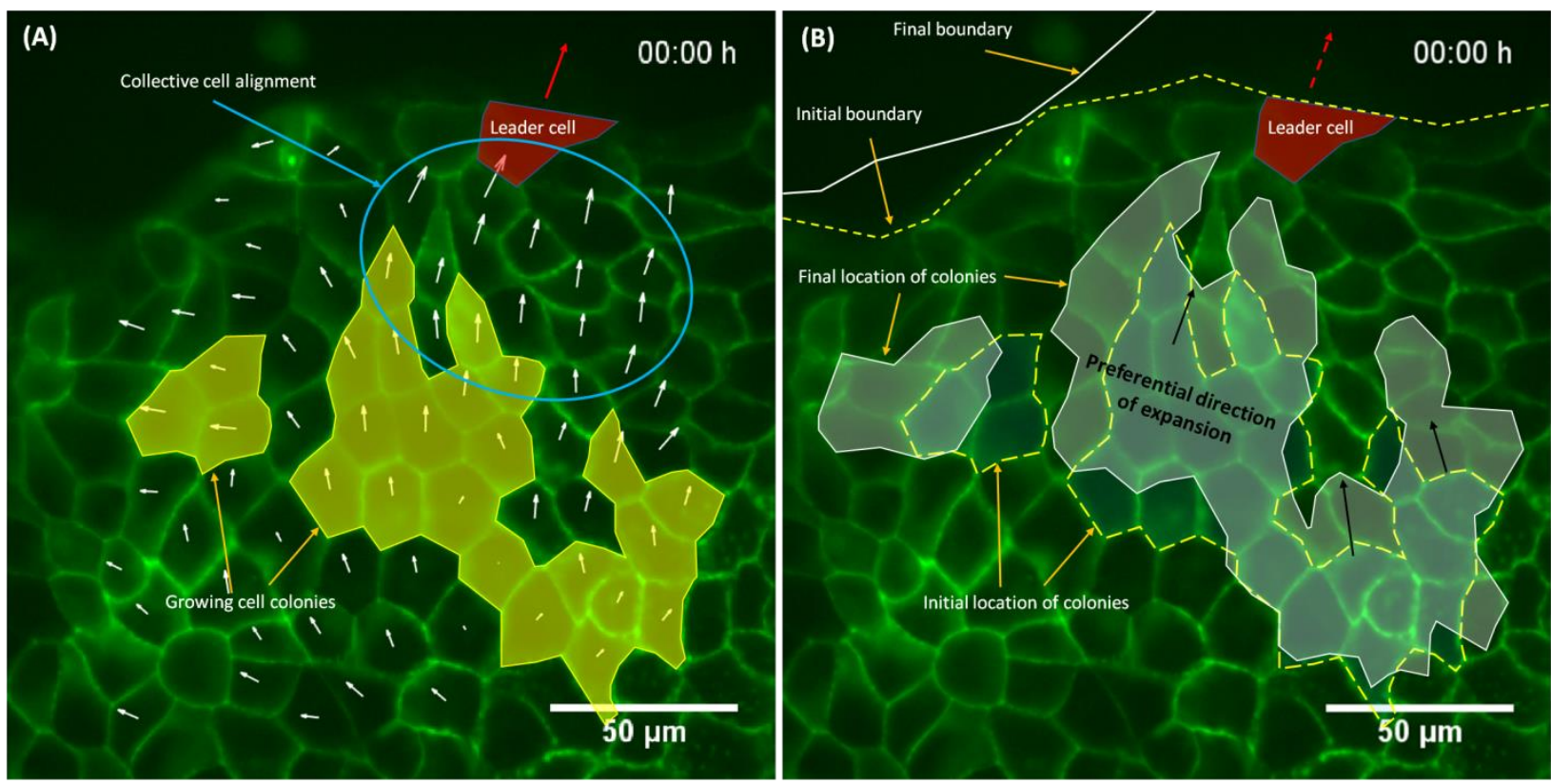

Figure S4. Expansion of static cell clusters. (A) A highly aligned velocity field was observed in the front cell rows of the growing cell colony. (B) Superimposing the initial and final location of the colonies to find the preferential direction of expansion. 